\title{
Interventricular septal angle can be used to predict which patients have combined postcapillary or precapillary pulmonary hypertension in left heart disease
}

Nehal Hussain ${ }^{1,2^{*}}$, David Capener ${ }^{2,1}$, Charlie Elliot ${ }^{1}$, Robin Condliffe ${ }^{1}, \operatorname{Jim}_{\mathrm{M}}$ Wild ${ }^{2}$, David G Kiely ${ }^{1}$, Andrew Swift ${ }^{2,1}$

From 18th Annual SCMR Scientific Sessions

Nice, France. 4-7 February 2015

\section{Background}

A transpulmonary gradient (TPG) $>12 \mathrm{mmHg}$ is thought to represent evidence of vascular change beyond that expected from passive pulmonary venous congestion in patients with pulmonary hypertension and left heart disease (PH-LHD). However recent studies found those with a diastolic pressure gradient (DPG) $>6$ to have a worse survival. This has led to a change in the recent guidelines suggesting 2 types of PH-LHD: "isolated post-capillary PH" (pulmonary arterial wedge pressure (PAWP) $>15 \mathrm{~mm}$ $\mathrm{Hg}$ and $\mathrm{DPG}<7 \mathrm{mmHg}$ ) and "combined postcapillary $\mathrm{PH}$ and pre-capillary PH" (PAWP $>15 \mathrm{~mm} \mathrm{Hg}$ and DPG $\geq 7$ $\mathrm{mmHg}$ ).

It would be advantageous if a non-invasive method of predicting DPG could be found for both prognostication and to identify potential patients for clinical trials of targeted therapies. Our aim was investigate the utility of cardiac magnetic resonance (CMR) imaging for estimation of DPG in patients with PH-LHD.

\section{Methods}

Patients with suspected pulmonary hypertension underwent CMR imaging at our unit between April 2012 and April 2014. Classification followed systematic evaluation with multimodality imaging and right heart catheterisation (RHC). Patients were diagnosed as PH-LHD if no other causes of PH could be identified and they fulfilled the following criteria: signs and symptoms of heart failure; mean pulmonary artery pressure (mPAP) $\geq 25 \mathrm{mmHg}$ at rest and pulmonary arterial wedge pressure $>15 \mathrm{mmHg}$ by RHC.

${ }^{1}$ Sheffield Pulmonary Vascular Diseases Unit, Hallamshire Hospital, Sheffield, UK

Full list of author information is available at the end of the article
TPG was defined mPAP-PAWP, and DPG was defined as diastolic PAP-PAWP.

A number of parameters were analysed including: right and left ventricular indexed volumes, ejection fractions and mass; aortic and pulmonary flow, pulmonary arterial area, and the inter-ventricular septal angle in systole and diastole.

\section{Results}

89 patients where found to have a diagnosis of PH-LHD. The average age was $70 y$ rs with $58 \%$ being female. Of these 89 patients, $67 \%$ were found to have a TPG $>12 \mathrm{mmHg}$, but only $26 \%$ had a DPG $>6 \mathrm{mmHg}$. No patients were found to have a raised TPG, but normal DPG. The average $\mathrm{mPAP}=44 \mathrm{mmHg} \quad(\mathrm{SD} \pm 11)$, $\mathrm{TPG}=23 \mathrm{mmHg}(\mathrm{SD} \pm 11)$, and $\mathrm{DPG}=5(\mathrm{SD} \pm 9)$. Systolic septal angle was the only CMR marker with a significant association with DPG, $(r=0.69, \mathrm{p}<0.0001)$. Receiver operating characteristics (ROC) curve of systolic septal angle against DPG $>6 \mathrm{mmHg}$ yielded an area under the curve (AUC) of 0.87. ROC curve analysis established a systolic septal angle of $>135^{\circ}$ to be the optimal threshold for distinguishing a normal DPG from those with a DPG $>6 \mathrm{mmHg}$ (sensitivity $100 \%$, specificity $79 \%$ ). In addition linear regression was used to derive coefficients to allow formulation of an equation estimating DPG from systolic septal angle: DPG=0.359xsystolic septal angle-51.

\section{Conclusions}

Systolic septal angle can be used to estimate whether a patient has "isolated post-capillary" or "combined postcapillary and pre-capillary" $\mathrm{PH}$. 


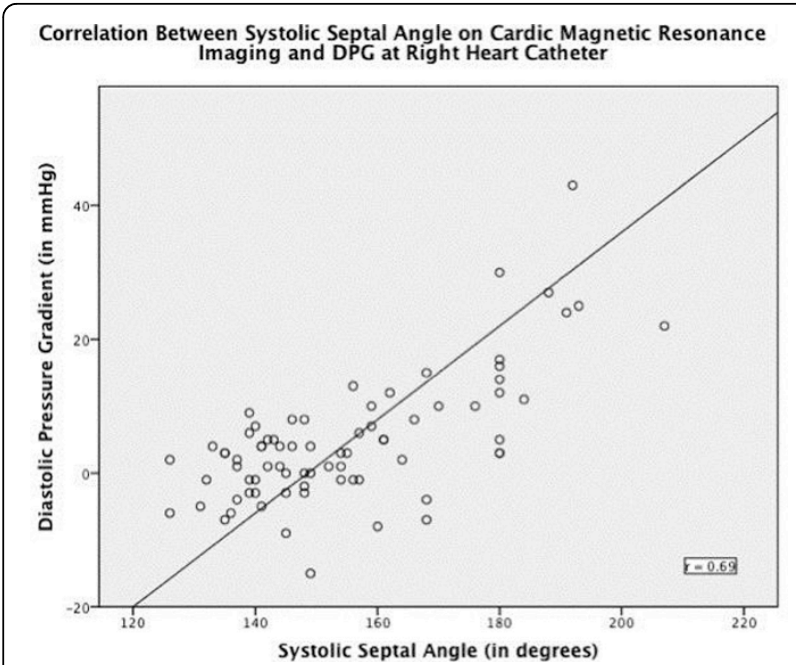

Figure 1

ROC curve of systolic septal angle and a DPG $>6 \mathrm{mmHg}$ at RHC

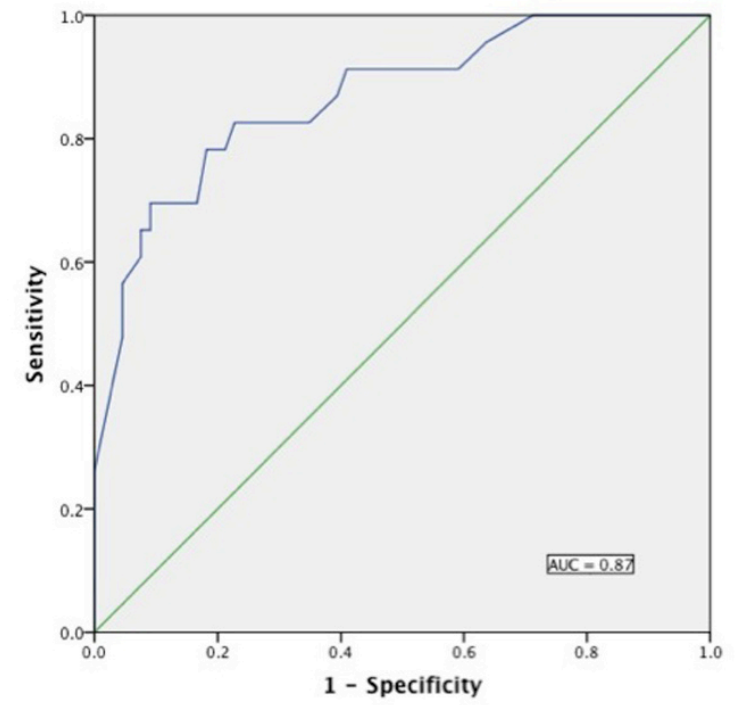

Figure 2

\section{Funding}

None.

\section{Authors' details}

${ }^{1}$ Sheffield Pulmonary Vascular Diseases Unit, Hallamshire Hospital, Sheffield, UK. ${ }^{2}$ Academic Radiology, Sheffield University, Sheffield, UK.

Published: 3 February 2015

doi:10.1186/1532-429X-17-S1-P338

Cite this article as: Hussain et al:: Interventricular septal angle can be used to predict which patients have combined postcapillary or precapillary pulmonary hypertension in left heart disease. Journal of Cardiovascular Magnetic Resonance 2015 17(Suppl 1):P338.

\section{Submit your next manuscript to BioMed Central} and take full advantage of:

- Convenient online submission

- Thorough peer review

- No space constraints or color figure charges

- Immediate publication on acceptance

- Inclusion in PubMed, CAS, Scopus and Google Scholar

- Research which is freely available for redistribution 